\title{
Toward effective prescription of inhaled corticosteroids in chronic airway disease
}

This article was published in the following Dove Press journal: International Journal of COPD

\author{
Zuzana Diamant ${ }^{1-3}$ \\ Guy Brusselle 4 \\ Richard E Russell ${ }^{5,6}$ \\ 'Department of Respiratory Medicine \\ and Allergology, Lund University, \\ Lund, Sweden; ${ }^{2}$ Department of \\ Clinical Pharmacy \& Pharmacology \\ University Medical Centre Groningen, \\ University of Groningen, Groningen, \\ the Netherlands; ${ }^{3}$ QPS-Netherlands, \\ University Medical Centre Groningen, \\ Groningen, the Netherlands; \\ ${ }^{4}$ Department of Respiratory Medicine, \\ Ghent University Hospital, Ghent, \\ Belgium; ${ }^{5}$ Respiratory Medicine Unit, \\ Nuffield Department of Medicine, \\ University of Oxford, Oxford, UK; \\ ${ }^{6}$ Lymington New Forest Hospital, \\ Southern Health National Health \\ Service Foundation Trust, Lymington, \\ Hampshire, UK
}

The airway diseases asthma and COPD affect millions of individuals worldwide. These diseases are major determinants of chronic morbidity and mortality, and represent a substantial public health burden..$^{2-4}$ Despite differences in etiology, clinical characteristics, and pathophysiology, both conditions share important features, such as airway obstruction and chronic airway inflammation. As a result of modern lifestyle, the incidence of both diseases is steadily increasing worldwide and effective preventive and treatment strategies are unmet needs. ${ }^{5}$

Traditionally, airway eosinophilia has been regarded as a major hallmark of asthma, whereas COPD has been associated with neutrophilic airway inflammation. ${ }^{6}$ For treatment of chronic inflammatory airway diseases, inhaled corticosteroids (ICS) are usually prescribed as maintenance therapy, most often as part of a combination therapy. While the majority of asthma patients generally respond well to ICS, ${ }^{7}$ this is not often the case in COPD ${ }^{8}$ Hence, reliable algorithms and easily implemented tools are needed to identify ICS responders in clinical practice, to optimize clinical benefits and minimize adverse events.

Over the past two decades, increasing insights into the pathobiology of chronic airway disease have enabled an understanding of its heterogeneous nature and thus helped to shape precision medicine. ${ }^{9}$ These novel insights are gradually being adapted by (inter)national guidelines for disease management in daily practice. In asthma, this has - among others - resulted in adding targeted therapies with biologicals for refractory allergic and/or eosinophilic asthma at treatment step 5 and, more recently, in adding house dust mite (HDM) sublingual immunotherapy for HDM-sensitized asthma patients uncontrolled on standard therapy in steps 3 and $4 .^{3}$

Until recently, the Global Initiative for Obstructive Lung Disease (GOLD) strategy did not differentiate across the COPD spectrum. ${ }^{10}$ For example, the GOLD-D category comprised three different phenotypes, ie, patients with a severe airway obstruction or frequent exacerbations, or both. Recent advances have led to the recognition that these different subsets may require different treatment approaches instead of the "one-size fits all" ICS-containing therapy as advocated in the treatment strategy at that time. ${ }^{10}$ This has resulted in default prescription of ICS for COPD patients. ${ }^{8}$

Increasing evidence of limited clinical effectiveness in distinct phenotypes, ${ }^{11-14}$ along with safety concerns associated with long-term use of high-dose ICS, ${ }^{15,33}$ has driven a personalized treatment strategy for chronic inflammatory airway disease recently proposed by an international expert panel. ${ }^{16}$

Precision medicine is the cornerstone of this innovative approach advocating identification and treatment of "treatable traits" in individual patients. ${ }^{17,18}$ In this
Correspondence: Richard E Russell Respiratory Medicine, NDM Research Building, Old Road Campus, University of Oxford, OX3 7FZ, Oxford, UK Email richard.russell@ndm.ox.ac.uk
International Journal of COPD 2018:13 3419-3424

(c) (1) (5) 2018 Diamant et al. This work is published and licensed by Dove Medical Press Limited. The full terms of this license are available at https://www.dovepress.com/terms.php (c) hereby accept the Terms. Non-commercial uses of the work are permitted without any further permission from Dove Medical Press Limited, provided the work is properly attributed. For permission for commercial use of this work, please see paragraphs 4.2 and 5 of our Terms (https://www.dovepress.com/terms.php). 
context, blood eosinophils as indicators of eosinophilic exacerbations have been identified as a "treatable trait". ${ }^{19,20}$ Data from several studies showed that benefits from ICS in COPD were limited to patients with frequent exacerbations and blood eosinophilia (the higher the initial blood eosinophil count the more the benefit). ${ }^{13,21}$ The recently updated GOLD classification is based on symptoms and exacerbations and hence provides a more differentiated treatment algorithm. ${ }^{22}$ Consequently, ICS therapy is only recommended for patients with frequent exacerbations uncontrolled on a combination of bronchodilators (ie, GOLD C and D). ${ }^{22}$ In this paper, we will provide a rationale toward more effective ICS prescription for patients with chronic inflammatory airway disease based on treatable traits.

\section{Over-prescription of inhaled corticosteroids in chronic inflammatory airway disease}

ICS have been available to treat chronic inflammatory airway disease for almost 70 years. ${ }^{23}$ Consequently, ICScontaining treatments have been amongst the most commonly prescribed and thus most profitable medications. ${ }^{24}$ This has enabled pharmaceutical companies to further develop this area of therapeutics. However, despite a massive level of prescription of (optimized) ICS and long-acting beta-agonist (LABA) combinations, many patients remain suboptimally controlled, ${ }^{25,26}$ with only small changes in morbidity and mortality of both asthma and COPD, while numbers of hospital admissions continue to rise increasing health care costs as a consequence. ${ }^{27}$ Although this may partly be ascribed to an increase in the prevalence of both conditions, we cannot attribute the clinical reality to this factor alone. Is it possible that many of the patients treated with ICS are either nonresponsive or respond suboptimally to this treatment?

Dogmatic prescription of ICS in chronic airway disease has resulted in a significant level of over-prescription. ${ }^{28}$ In asthma, awareness of the potential for a customized approach to ICS prescription has been incorporated into the guidelines advocating a step-down regime after control has been reached. Moreover, guidelines now accept a role for a more flexible maintenance and rescue from the use of ICS/ LABA combinations. ${ }^{29}$ In COPD, the efficacy of ICS therapy has been investigated for over 25 years now. Initially, it was assumed that the benefits seen in many asthma patients would be transferrable to those with COPD. Large scale studies were performed with high doses of ICS, all of which were either negative or demonstrated modest benefits at best. ${ }^{30}$ No protection was observed against a decline in lung function and overall, only modest effects on exacerbations and quality of life were seen. ${ }^{31}$ Despite these findings, in clinical practice, ICS continued to be prescribed to COPD patients at every level of lung function deficit and for every disease category as defined by the GOLD approach. ${ }^{8}$ Moreover, ICS are prescribed for at least $40 \%$ of smokers presenting with symptoms without any measurable lung function abnormality. ${ }^{28,32}$ In these individuals, there is no evidence to support the use of ICS.

The results of the over-prescription of ICS affect all parties involved. First, the individuals treated erroneously are being exposed to medication they do not actually need along with the potential for side effects (eg, oropharyngeal candidiasis, dysphonia, skin bruising, osteoporosis, cataract, loss of diabetic control, and pneumonia). ${ }^{33-35}$ Second, the prescribers feel that they are treating their patient and thus do not reflect on other - more effective - therapies, and, finally, the insurance ends up paying for ineffective medication and is thus unable to fund much more cost-effective approaches in the long term (smoking cessation, bronchodilators, pulmonary rehabilitation).

Prescribing ICS on a "one size fits all basis" could be justified in the early years because this was the only available medication option. Presently, prescribing by default is no longer acceptable and a more personalized approach based on treatable traits should be encouraged.

\section{From "one size fits all" toward personalized treatment}

In many ways, proposing a more precise approach to the prescription of ICS may seem contradictory, as corticosteroids are a non-precise treatment by their very mechanism of action. Nevertheless, it is crucial for physicians to appropriately prescribe ICS to ensure effectiveness and limit side effects. Both for asthma and COPD, utilizing biomarkers has been shown to aid the diagnosis, to predict exacerbations and to drive treatment. ${ }^{36,37}$ In this respect, fractionated exhaled nitric oxide (FeNO) and blood eosinophils are easily measurable biomarkers that can be used to predict and to monitor treatment response and adherence to ICS. ${ }^{16,38,39}$

Currently, there is increasing understanding that both asthma and COPD are heterogeneous disorders with overlapping characteristics. ${ }^{3,9,18}$ Even though at times they may appear to be clinically indistinguishable, cluster analyses have identified distinct clinical, biological, and pathological clusters with different responses to treatment. ${ }^{7,20,40-43}$ Importantly, cluster analyses can link inflammatory phenotypes to treatment algorithms. For instance, the hierarchical cluster 
analysis by Haldar et al on data from over 400 asthma patients revealed five different phenotypic clusters based on concordance between symptoms, sputum eosinophilia, and the response to ICS. ${ }^{7}$

Patients with concordant symptoms and sputum eosinophilia presented with milder, often atopic disease, with an overall good response to ICS and a benign disease course, while those with discordant symptoms or inflammation usually presented with a more complex disease with varying response to ICS. Similar observations have been previously made in a number of clinical studies. ${ }^{44,45}$ Overall, these findings support a symptom-guided approach to management for mild to moderate, "concordant"-type asthma, while "discordant"-type, refractory asthmatics might benefit from inflammatory biomarker-guided, personalized therapeutic options including targeted therapy with biologics.

How do these findings relate to COPD? ISOLDE was one of the first studies to investigate the effect of ICS on the rate of decline in lung function in COPD patients. The study was negative for its primary end point. ${ }^{31}$ However, data from a post hoc analysis of the ISOLDE study revealed that patients with moderate to severe COPD with persistent blood eosinophilia of $\geq 2 \%$ show an accelerated lung function decline that can be prevented by ICS treatment, while ICS did not affect lung function decline in patients with blood eosinophila $<2 \% .{ }^{46}$ This compelling evidence in combination with novel insights into underlying disease mechanisms urged a panel of international experts to propose a personalized approach to chronic inflammatory airway disease management beyond clinical labels. ${ }^{17,18}$ Hence, the concept of "treatable traits" was conceived, implementing precision medicine into clinical practice.

These insights based on emerging data from large clinical trials helped to further shape the updated GOLD strategy. ${ }^{22}$ This update has reclassified COPD and emphasizes the dual goals of symptom control and reduction in risk of exacerbation. Presently, optimal bronchodilator therapy, often comprising a LABA with a long-acting muscarinic antagonist (LAMA) in a fixed dose combination (FDC), is the cornerstone of COPD treatment. ${ }^{22}$ This combination treatment decreases both the static and dynamic hyperinflation, which helps to optimize lung function, daily activities, to improve exercise capacity and endurance, and the overall quality of life. ${ }^{47-49}$ LABA-LAMA bronchodilator combination therapy has been recommended based on the outcomes of large randomized controlled trials including the recently published FLAME study..$^{50}$ This large prospective study showed superiority of the LABA-LAMA combination in preventing exacerbations in patients with COPD as compared to those on a fixed ICS-LABA combination, irrespective of baseline blood eosinophils. ${ }^{51}$ The study had tightly controlled inclusion criteria which excluded participants with baseline eosinophils $>600$ cells $/ \mu \mathrm{L}$, and the run-in period excluded ICS with the potential that eosinophilic participants will become unstable and be excluded. During this 52-week study, the incidence of pneumonia was significantly higher in patients on ICS-LABA compared to those on LABA-LAMA combination $(4.8 \%$ vs $3.2 \%$, $p=0.02$ ). These findings are in line with previous large studies investigating the effect of ICS (containing) therapy on exacerbations, lung function decline, and mortality in COPD which could not demonstrate substantial or additional clinical benefits of ICS in many patients over time. ${ }^{31,51-54}$ Several other studies have examined the risk benefit of the use of ICS and also ICS withdrawal. ${ }^{16,53-59}$ Specifically, during the 12-month study (WISDOM) that included patients with (very) severe COPD taking tiotropium plus salmeterol, the risk of moderate or severe exacerbations was similar among those who discontinued ICS and those on ICS cotreatment. ${ }^{52}$ A recent post hoc analysis showed that only patients with at least one exacerbation in the previous year and a high blood eosinophil count (ie, $\geq 300$ cells $/ \mu \mathrm{L}$ or $\geq 4 \%$ ) at baseline were at increased risk of an exacerbation after complete ICS withdrawal, representing a minority of the entire study population $(n=2296) .{ }^{58}$ Indeed, other studies confirmed that blood eosinophils may further help to identify COPD patients with frequent exacerbations as a distinct phenotype that may benefit from ICS, while eosinophilic airway inflammation has been proposed as a "treatable trait". 8,17,20,59

Consequently, it is crucial to critically assess the benefits versus risks in the individual COPD patient and positively prescribe ICS based on phenotype-related treatable traits. ${ }^{17,18}$ The updated GOLD strategy now better reflects this personalized approach. ${ }^{22}$

\section{Changing of guidelines?}

The future management of inflammatory airways disease is potentially very exciting. We believe that given the ample supportive evidence, which is shaping the current guidelines, the journey toward a "treatable trait" approach can really start. Our goal must be to give more effective therapy to patients who will respond - this applies not only to targeted treatments with biologic agents or small molecules but also existing therapy with ICS - and thus improve disease outcome while reducing the side effects of unnecessary 
pharmacotherapy. An aspirational goal should be to never have to prescribe oral corticosteroids again to any patient with a proven inflammatory airways disease. ${ }^{16}$

To be able to move forward, we need to have a clear and accurate diagnosis. Focusing on obtaining information as to the individual patient's symptoms, comorbidities and pathophysiology (clinical phenotype) complemented with the inflammatory phenotype. Based on these individual characteristics, the correct treatment can be initiated. Presently, ICS with or without the addition of LABA are considered the basis of asthma pharmaceutical treatment. Comorbidities should be treated, and treatment should be adjusted/reconsidered with the goal of achieving optimal control of symptoms, reducing the risk of acute exacerbations and improving the patient's daily activities/quality of life.

COPD treatment goals are similar: improving symptoms (dyspnea), reducing the risk of acute exacerbations, and improving quality of life. Apart from pharmacotherapy, non-drug treatment modalities are helpful to achieve optimal outcomes in COPD patients. Smoking cessation is essential in combination with bronchodilator therapy, to improve dyspnea, while the opportunity for pulmonary rehabilitation should not be missed. Although challenging to many patients, pulmonary rehabilitation and necessary lifestyle adjustments are often critical to improve and reverse loss of lung function and exercise endurance. Bronchodilator therapy in COPD should always be optimized, ie, a combination of a LAMA and a LABA, now available as a FDC. Finally, based on the clinical phenotype stratification according to GOLD, we should make further treatment decisions based upon a detailed assessment of the underlying inflammatory mechanisms (inflammatory phenotype). Clinical (GOLD) phenotype should, at present, be given primacy when making decisions to intensify therapy - especially moving triple therapy with ICS - as we lack definitive prospective data as to the utility of a true focused "treatable trait" prescription approach. However, it is clear that simply measurable and available biomarkers such as FeNO and blood eosinophil counts may help to predict a favorable response to ICS not only in asthma but also in COPD. More biomarkers will emerge and the use of a composite approach may have even more clinical utility, leading to mechanistic insights as well as directing disease modifying therapy such as new biological agents and small molecule inhibitors of specific inflammatory pathway targets.

In summary, our goals for patients with asthma should be: to have minimal (none) symptoms, be free of restrictions in daily activities, and patients should never die of their disease. All patients should have their treatment titrated to the lowest level required to achieve and maintain these goals. COPD patients should be treated with the goal of reversing the disability that years of accelerated lung function decline have caused with a reduction in risk of exacerbations. This will be best achieved by a personalized approach, leading to an individual understanding of risks and benefits. The correct treatments should be given to the patients who will achieve the maximum benefit with the minimum risk. With current therapies, such management goals are within our grasp, although taking an individualized approach to management will maximize benefit and minimize risk.

\section{Disclosure}

The authors report no conflicts of interest in this work.

\section{References}

1. Murray CJL, Lopez AD. Measuring the global burden of disease. N Engl J Med. 2013;369(5):448-457.

2. Bateman ED, Hurd SS, Barnes PJ, et al. Global strategy for asthma management and prevention: GINA executive summary. Eur Respir J. 2008;31(1):143-178.

3. 2018 GINA Report, Global Strategy for Asthma Management and Prevention. Available from: http://ginasthma.org/2017-gina-reportglobal-strategy-for-asthma-management-and-prevention/. Accessed April 24, 2018.

4. Vogelmeier CF, Criner GJ, Martinez FJ, et al. Chronic obstructive pulmonary disease. Eur Respir J. 2017;12(1):433-438.

5. Soriano JB, Abajobir AA, Abate KH, et al. Global, regional, and national deaths, prevalence, disability-adjusted life years, and years lived with disability for chronic obstructive pulmonary disease and asthma, 1990-2015: a systematic analysis for the Global Burden of Disease Study 2015. Lancet Respir Med. 2017;5(9):691-706.

6. Keatings VM, Barnes PJ. Granulocyte activation markers in induced sputum: comparison between chronic obstructive pulmonary disease, asthma, and normal subjects. Am J Respir Crit Care Med. 1997;155(2):449-453.

7. Haldar P, Pavord ID, Shaw DE, et al. Cluster analysis and clinical asthma phenotypes. Am J Respir Crit Care Med. 2008;178(3):218-224.

8. Brusselle G, Price D, Gruffydd-Jones K, et al. The inevitable drift to triple therapy in COPD: an analysis of prescribing pathways in the UK. Int J Chron Obstruct Pulmon Dis. 2015;10:2207-2217.

9. Sterk PJ. Chronic diseases like asthma and COPD: do they truly exist? Eur Respir J. 2016;47(2):359-361.

10. GOLD COPD Strategy. 2014. Available from: www.GOLDCOPD.org. Accessed April 24, 2018.

11. Perera WR, Hurst JR, Wilkinson TMA, et al. Inflammatory changes, recovery and recurrence at COPD exacerbation. Eur Respir J. 2007;29(3): 527-534.

12. Wedzicha JA. Antibiotics at COPD exacerbations: the debate continues. Thorax. 2008;63(11):940-942.

13. Willson J, Bateman ED, Pavord I, Lloyd A, Krivasi T, Esser D. Cost effectiveness of tiotropium in patients with asthma poorly controlled on inhaled glucocorticosteroids and long-acting $\beta$-agonists. Appl Health Econ Health Policy. 2014;12(4):447-459.

14. Magnussen $H$, Tetzlaff $K$, Calverley PMA. Inhaled glucocorticoids and COPD exacerbations. N Engl J Med. 2015;372(1):93-94.

15. Price DB, Russell R, Mares R, et al. Metabolic effects associated with ICS in patients with COPD and comorbid type 2 diabetes: a historical matched cohort study. PLoS One. 2016;11(9):e0162903.

16. Pavord ID, Beasley R, Agusti A, et al. After asthma: redefining airways diseases. Lancet. 2018;391(10118):350-400. 
17. Agusti A, Bel E, Thomas M, et al. Treatable traits: toward precision medicine of chronic airway diseases. Eur Respir J. 2016;47(2):410-419.

18. Agusti A, Bafadhel M, Beasley R, et al. Precision medicine in airway diseases: moving to clinical practice. Eur Respir J. 2017;50(4).pii: 1701655 .

19. Bafadhel M, Greening NJ, Harvey-Dunston T, et al. Severe hospitalised exacerbations of COPD with an eosinophilic phenotype have favourable outcomes with prednisolone therapy sub-analysis from a prospective multi-centre randomised control trial. Thorax. 2013;68 (Suppl III):A16.

20. Bafadhel M, McKenna S, Terry S, et al. Acute exacerbations of chronic obstructive pulmonary disease: identification of biologic clusters and their biomarkers. Am J Respir Crit Care Med. 2011;184(6):662-671.

21. Pavord ID, Lettis S, Locantore N, et al. Blood eosinophils and inhaled corticosteroid/long-acting beta-2 agonist efficacy in COPD. Thorax. 2016;71(2):118-125.

22. GOLD 2018 Global Strategy for the Diagnosis, Management and Prevention of COPD. Available from: http://goldcopd.org/gold2017-global-strategy-diagnosis-management-prevention-copd/. Accessed April 24, 2018.

23. Gelfand ML. Administration of cortisone by the aerosol method in the treatment of bronchial asthma. N Engl J Med. 1951;245(8):293-294.

24. Moon JC, Flett AS, Godman BB, Grosso AM, Wierzbicki AS. Getting better value from the NHS drug budget. BMJ. 2010;341:c6449.

25. Bateman ED, Boushey HA, Bousquet J, et al. Can guideline-defined asthma control be achieved? The Gaining Optimal Asthma ControL study. Am J Respir Crit Care Med. 2004;170(8):836-844.

26. Rabe KF, Vermeire PA, Soriano JB, Maier WC. Clinical management of asthma in 1999: the Asthma Insights and Reality in Europe (AIRE) study. Eur Respir J. 2000;16(5):802-807.

27. Suruki RY, Daugherty JB, Boudiaf N, Albers FC. The frequency of asthma exacerbations and healthcare utilization in patients with asthma from the UK and USA. BMC Pulm Med. 2017;17(1):74.

28. Price D, West D, Brusselle G, et al. Management of COPD in the UK primary-care setting: an analysis of real- life prescribing patterns. Int J Chron Obstruct Pulmon Dis. 2014;9:889-904.

29. Levy ML, Thomas M, Small I, Pearce L, Pinnock H, Stephenson P. Summary of the 2008 BTS/SIGN British Guideline on the management of asthma. Prim Care Respir J. 2009;18(Suppl 1):S1-S16.

30. Ford PA, Russell RE, Barnes PJ. ICS and COPD: time to clear the air. Int J Chron Obstruct Pulmon Dis. 2009;4:289-290.

31. Burge PS, Calverley PM, Jones PW, Spencer S, Anderson JA, Maslen TK. Randomised, double blind, placebo controlled study of fluticasone propionate in patients with moderate to severe chronic obstructive pulmonary disease: the ISOLDE trial. BMJ. 2000;320(7245):1297-1303.

32. White P, Thornton H, Pinnock H, Georgopoulou S, Booth HP. Overtreatment of COPD with inhaled corticosteroids -iImplications for safety and costs: cross-sectional observational study . PLoS One. 2013; 8(10): e75221.

33. Suissa S, Kezouh A, Ernst P. Inhaled corticosteroids and the risks of diabetes onset and progression. Am J Med. 2010;123(11):1001-1006.

34. Suissa S, Barnes PJ. Inhaled corticosteroids in COPD: the case against. Eur Respir J. 2009;34(1):13-16.

35. Price DB, Russell R, Mares R, et al. Metabolic effects associated with ICS in patients with COPD and comorbid type 2 diabetes: a historical matched cohort study . PLoS One. 2016;11(9):e0162903.

36. Diamant Z, Boot JD, Mantzouranis E, Flohr R, Sterk PJ, Gerth van Wijk R. Biomarkers in asthma and allergic rhinitis. Pulm Pharmacol Ther. 2010;23(6):468-481.

37. Parulekar AD, Diamant Z, Hanania NA. Role of T2 inflammation biomarkers in severe asthma. Curr Opin Pulm Med. 2016;22(1):59-68.

38. Martin MJ, Wilson E, Gerrard-Tarpey W, et al. The utility of exhaled nitric oxide in patients with suspected asthma. Thorax. 2016;71(6):562-564.

39. Bafadhel M, Pavord ID, Russell REK. Eosinophils in COPD: just another biomarker? Lancet Respir Med. 2017;5(9):747-759.
40. Burgel P-R, Paillasseur J-L, Peene B, et al. Two distinct chronic obstructive pulmonary disease (COPD) phenotypes are associated with high risk of mortality. PLoS One. 2012;7(12):e51048.

41. Moore WC, Meyers DA, Wenzel SE, et al. Identification of asthma phenotypes using cluster analysis in the Severe Asthma Research Program. Am J Respir Crit Care Med. 2010;181(4):315-323.

42. Sendin-Hernandez MP, Avila-Zarza C, Sanz C, et al. Identification of five chronic obstructive pulmonary disease subgroups with different prognoses in the ECLIPSE cohort using cluster analysis. Am J Respir Crit Care Med. 2017;72(1):63-72.

43. Weatherall M, Travers J, Shirtcliffe PM, et al. Distinct clinical phenotypes of airways disease defined by cluster analysis. Eur Respir J. 2009;34(4):812-818.

44. Green RH, Brightling CE, McKenna S, et al. Asthma exacerbations and sputum eosinophil counts: a randomised controlled trial. Lancet. 2002;360(9347):1715-1721.

45. Woodruff PG, Modrek B, Choy DF, et al. T-helper type 2-driven inflammation defines major subphenotypes of asthma. Am J Respir Crit Care Med. 2009;180(5):388-395.

46. Barnes NC, Sharma R, Lettis S, Calverley PMA. Blood eosinophils as a marker of response to inhaled corticosteroids in COPD. Eur Respir J. 2016;47(5):1374-1382.

47. Di Marco F, Sotgiu G, Santus P, et al. Long-acting bronchodilators improve exercise capacity in COPD patients: a systematic review and meta-analysis. Respir Res. 2018;19(1):18.

48. Buhl R, Gessner C, Schuermann W, et al. Efficacy and safety of oncedaily QVA149 compared with the free combination of once-daily tiotropium plus twice-daily formoterol in patients with moderate-to-severe COPD (QUANTIFY): a randomised, non-inferiority study. Thorax. 2015;70(4):311-319.

49. Beeh K-M, Westerman J, Kirsten A-M, et al. The 24-h lung-function profile of once-daily tiotropium and olodaterol fixed-dose combination in chronic obstructive pulmonary disease. Pulm Pharmacol Ther. 2015;32:53-59.

50. Wedzicha JA, Banerji D, Chapman KR, et al. Indacaterol-glycopyrronium versus salmeterol-fluticasone for COPD. $N$ Engl J Med. 2016;374(23):2222-2234

51. Roche N, Chapman KR, Vogelmeier CF, et al. Blood eosinophils and response to maintenance chronic obstructive pulmonary disease treatment. data from the FLAME trial. Am J Respir Crit Care Med. 2017;195(9):1189-1197.

52. Magnussen H, Watz H, Kirsten A, et al. Stepwise withdrawal of inhaled corticosteroids in COPD patients receiving dual bronchodilation: WISDOM study design and rationale. Respir Med. 2014;108(4): 593-599.

53. Magnussen H, Disse B, Rodriguez-Roisin R, et al. Withdrawal of inhaled glucocorticoids and exacerbations of COPD. $N$ Engl J Med. 2014;371(14):1285-1294.

54. Suissa S, Rossi A. Weaning from inhaled corticosteroids in COPD: the evidence. Eur Respir J. 2015;46(5):1232-1235.

55. Rossi A, van der Molen T, del Olmo R, et al. INSTEAD: a randomised switch trial of indacaterol versus salmeterol/fluticasone in moderate COPD. Eur Respir J. 2014;44(6):1548-1556.

56. Wouters EFM, Postma DS, Fokkens B, et al. Withdrawal of fluticasone propionate from combined salmeterol/fluticasone treatment in patients with COPD causes immediate and sustained disease deterioration: a randomised controlled trial. Thorax. 2005;60(6):480-487.

57. van der Valk P, Monninkhof E, van der Palen J, Zielhuis G, van Herwaarden C. Effect of discontinuation of inhaled corticosteroids in patients with chronic obstructive pulmonary disease: the COPE study. Am J Respir Crit Care Med. 2002;166(10):1358-1363.

58. Watz H, Tetzlaff K, Wouters EFM, et al. Blood eosinophil count and exacerbations in severe chronic obstructive pulmonary disease after withdrawal of inhaled corticosteroids: a post-hoc analysis of the WISDOM trial. Lancet Respir Med. 2016;4(5):390-398.

59. Pavord ID, Lettis S, Anzueto A, Barnes N. Blood eosinophil count and pneumonia risk in patients with chronic obstructive pulmonary disease: a patient-level meta-analysis. Lancet Respir Med. 2016;4(9):731-741. 
Dove Medical Press encourages responsible, free and frank academic debate. The content of the International Journal of Chronic Obstructive Pulmonary Disease 'Editorial' section does not necessarily represent the views of Dove Medical Press, its officers, agents, employees, related entities or the International Journal of Chronic Obstructive Pulmonary Disease editors. While all reasonable steps have been taken to confirm the content of each Editorial, Dove Medical Press accepts no liability in respect of the content of any Editorial, nor is it responsible for the content and accuracy of any Editorial.

International Journal of COPD

Dovepress

\section{Publish your work in this journal}

The International Journal of COPD is an international, peer-reviewed journal of therapeutics and pharmacology focusing on concise rapid reporting of clinical studies and reviews in COPD. Special focus is given to the pathophysiological processes underlying the disease, intervention programs, patient focused education, and self management protocols.

This journal is indexed on PubMed Central, MedLine and CAS. The manuscript management system is completely online and includes a very quick and fair peer-review system, which is all easy to use. Visit http://www.dovepress.com/testimonials.php to read real quotes from published authors.

Submit your manuscript here: http://www.dovepress.com/international-journal-of-chronic-obstructive-pulmonary-disease-journal 